\title{
Evaluation of the isolation protocols of primary cells from common carp (Cyprinus carpio L.) skin tissue
}

\author{
M.F. Hasoon \\ Scientific Research Center, College of Science, Duhok University, Kurdistan Region, Iraq, Email: mayada.hasoon@uod.ac
}

(Received November 29, 2017; Accepted December 12, 2017)

\begin{abstract}
In this study, pieces of skin from common carp (Cyprinus carpio L.) fish were collected freshly from juveniles from a privet fish farm in Duhok city, Kurdistan-Iraq. Those pieces of skin were cultured In Vitro by using two methods of explanting; direct explants and enzymatic pre-digested explants of tissue fragments. The results showed a highest cell yield $\left(5 \times 10^{3} \mathrm{cell} / \mathrm{ml}\right)$ on passage 2 of enzymatic pre-digested tissues and higher cell growth rate in compare with cell yield $\left(38 \times 10^{2}\right.$ cell $/ \mathrm{ml}$ ) gained from direct explant tissues. Both procedures showed forming of clumped cells colonies in initial passages (P1 and P2), and the morphological changes were developed in both cells to show a fibroblast like appearance thereafter. Such findings are important and advantageous to suggest a faster and more efficient protocol for tissue culture cells isolation with lower cost and better isolation success as well.
\end{abstract}

Keywords: Tissue Culture; Isolation Method; Fish Skin, Enzymatic Explants Available online at http://www.vetmedmosul.org/ijvs

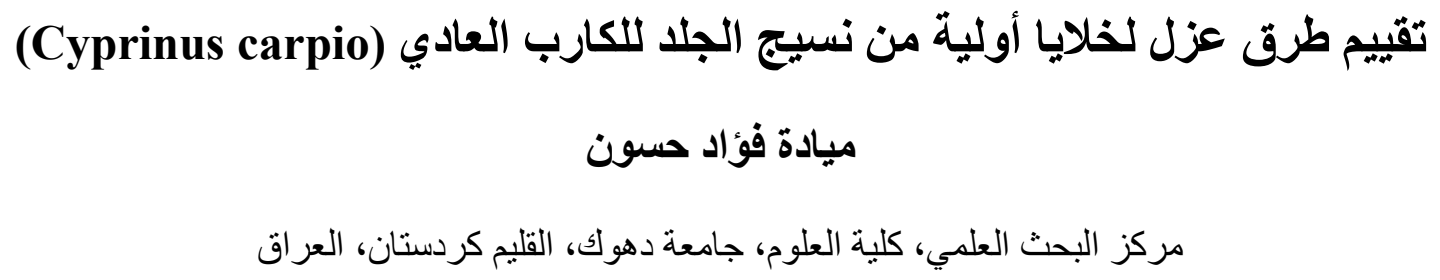

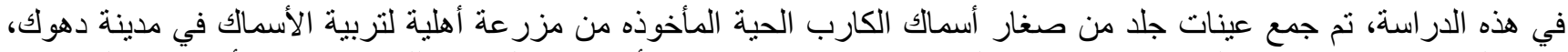

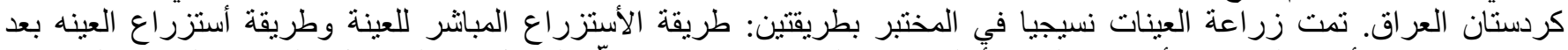

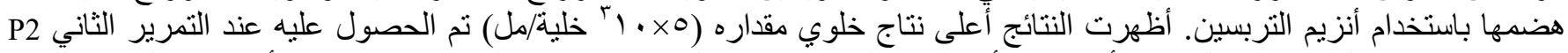

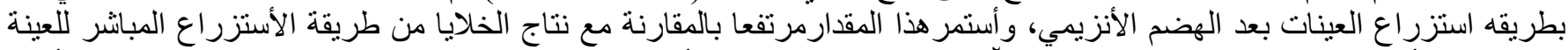

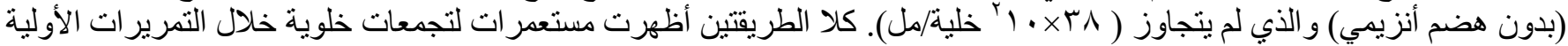

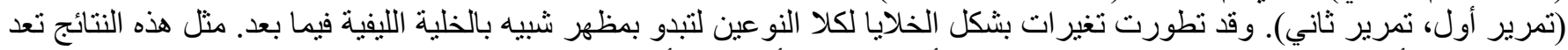

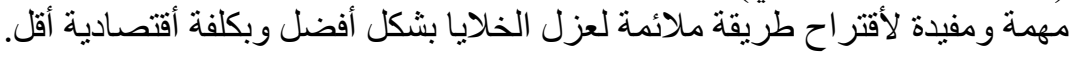

\section{Introduction}

During the last decades, it has been well accepted that fish can be considered as a source for tissue culture cells (1). Therefore, many studies investigated the isolation and expansion of cells isolated from carp fish tissues (1). Because fish skin is the biggest part of fish that covers all the body, it can be considered a rich source for fibroblast- like cells isolation (2), many groups reported that isolation of tissue culture cells from different parts of skin tissue matrix with various derivation protocols (1).

Skin tissue that during fish life development is responsible for protection is mainly composed from collagen, and there is a close similarity in the composition of skin and muscle collagens in fish (3). Clinically, isolated cells have to be expanded in order to reach the high 
quantities required for different applications. The role of isolation processes is extremely important since if they were efficient they are responsible for maximizing the cell yield starting with an unrefined source maintaining and also the functional identity of the isolated cells (4). Some laboratories have used EDTA instead of collagenase or trypsin as cell disaggregating substance for primary cell culture (6). Recently (5) have used EDTA as matrix for cell attachment; others replaced EDTA with trypsine enzyme. But reports are still lacking regarding the protocols used for isolation of fish cell culture.

Primary culture of fish cells has been used as an ideal model for various studies like substrate utilization (1-4), xenobiotic metabolism, thermal stress, monitoring of aquatic pollution, etc. $(5,6)$. During past few years techniques have been developed for primary culture of fish cells but the optimization of the protocol and conditions necessary for disaggregation of the cells, seeding, maintenance and culture conditions were variable (7-10). One of the major constraints seems to be the inability of fish cells, especially skin fibroblast to attach firmly to culture substrate $(1,7,11)$. Suspension culture of trout hepatocytes has been attempted (12), but this always results in low metabolic viability or fragility of cell attachments $(1,7)$. Today, it is a common practice that some sort of matrix is necessary for firm attachment of cells in shortterm as well as long-term culture; however, there appears no consensus on the nature of the substrate (1). During recent years large number of specific cell adhesion molecules such as fibronectin, vitronectin, laminin, collagen and their cell surface receptors have been characterised (13-15). Culture of fish skin has been tried in attachment proteins both from mammalian $(2,3,10,16)$ as well as piscine origin (4,7-9). Attempts have also been made to assess the comparative efficiency of mammalian as well as fish collagens as matrix using same fish cell lines and it has been found that fish collagen is better than calf collagen with respect to attachment and spreading cells (11). Although, fish skin collagen has been well characterised (17-20) still there appears to be no wide agreement regarding its use as an attachment factor for fish cell culture. Investigations are still lacking about the use of collagen substrate from one species of fish for interspecific / intergeneric use.

The objective and purpose of this study is; to introduce isolation of cells from whole fish skin tissue suggested new method (a combination of two methods; explants of enzymatic processed tissue as mixed pre-enzymatic explant protocol) to faster and better extraction of cells from collagenous tissue of fish skin. Morphological changes of isolated cells were compared between different methods of isolation. The present study aims to identify the current methods of cell isolation from fish skin tissue as well as to identify their critical steps in details and to find out a cheap and easily protocol with available substance to be used for isolation of primary cells and also a suitable matrix for the culture of fish skin cells in vitro.

\section{Material and methods}

\section{Materials}

Phosphate-buffered saline (PBS) Sigma (St. Louis, MO), fetal bovine serum (FBS) (Gipco®), (CGM) Complete Growth Medium (L-15; Leibovitz 15) with Lglutamine Sigma (St. Louis, MO), antibiotic (penicillinstreptomycin) Sigma (St. Louis, MO) and amphotericin B, (HEPES; 4- (2-hydroxyethyl)-1-piperazineethanesulfonic acid) Sigma (St. Louis, MO), trypsin-EDTA; Ethylene diamine tetra acetic acid Sigma (St. Louis, MO).All chemicals were used directly without further purification and the steps of cells isolation have been done in the tissue culture unit, Scientific Research Center, Faculty of Science/ Duhok Univ.

\section{Methods}

According to the protocol described by (21) the work was divided into four steps; isolation phases (by direct explant of tissue or enzymatic pre-digested explant of enzymatic digested tissue), expansion (subculture passages) of cells, morphological description and viability index evaluation of cells in terms of cell count and sub-culture passages.

\section{Collection of samples}

All fish samples, were subjected for gross and dissecting microscope (MOTIC ST-39 SERIES) inspection according to the procedure described by $(22,23)$ to investigate presence of any external parasites that might cause skin tissue damage in examined fish.

All of skin tissue samples were collected freshly from common carp juveniles, 5-7 cm length (from a privet farm in Duhok city). Immediately after fish collection, the samples were transferred by cool, aerated box to the tissue culture unit/ Scientific Research Center, Faculty of Science, Duhok Univ. All the procedure of collection and transportation was performed under sterile conditions. Briefly, the procedure was performed by anesthetizing the fish (immersing gradually in ice-cold water) on room temperature (24), then pithing the fish with a sharp sterile probe at the junction between the skull and the first cervical vertebrate for destroying the nerve tissue (25). Directly after pithing, the samples of skin were cleaned by the removal of the remaining muscles (meat), fins, and scales. The skins were dipped in 70\% ethanol for few seconds, and then rinsed with sterile PBS (Phosphate Buffer Saline) and cut into small pieces with a sterile sharp scissor. 


\section{Isolation of cells}

Isolation and propagation of tissue culture cells from small pieces of skin was carried out according to the protocol described by (17). Skin cells isolation was performed in cold, sterile dissection solution consisting of $1 \%$ antibiotic solution in PBS to give $100 \mathrm{U} / \mathrm{mL}$ penicillin, $100 \mathrm{mg} / \mathrm{mL}$ streptomycin, and $0.25 \mathrm{mg} / \mathrm{mL}$ amphotericin B. Briefly, in laminar hood (class/2) and under sterile conditions, each piece of skin was cut by sterile scissor into smaller $2-3 \mathrm{~cm}$ length pieces. The skin was washed gently three times with PBS supplied with $2 \%$ antibiotic and squeezed with curved forceps to remove trapped blood within the blood vessels. The washing was repeated until remove all blood and blood clots. After washing, horizontal sections were made in each piece by using a sterile scalpel then cut sections with sterile scissors and forceps into tiny small pieces $\left(1-3 \mathrm{~mm}^{3}\right)$ of tissue sections to extract cells. Then, the tiny pieces washed again with sterile PBS solution to be ready for explant culturing $(12,15)$.

\section{Explants procedure}

For explant outgrowth, 1-3 $\mathrm{mm}^{3}$ small cut pieces were washed twice with sterile PBS (containing 1\% antibiotic). Then, transferred directly into tissue culture flask $\left(25 \mathrm{~cm}^{2}\right)$ and were left undisturbed for 5-10 minutes until good attachment onto flask ground. Then, 7-10ml of complete growth medium (CGM) composed of L-15 (high glucose) with $2 \mathrm{mM}$ L-glutamine, supplemented with $20 \%$ fetal bovine serum, $100 \mathrm{U}$ penicillin/streptomycin was added to cover the explanted pieces. The culture flask was left undisturbed for $3-4$ days and maintained at $26^{\circ} \mathrm{C}$ in a humidified atmosphere. The medium changed every $2-3$ days thereafter $(12,15)$.

\section{Explants of enzymatic digested tissue}

In this procedure, the small minced pieces of tissue (1-3 $\mathrm{mm}^{3}$ ) were washed with PBS then placed in $50 \mathrm{ml}$ Erlenmeyer glass flask to be covered with an appropriate amount of the enzymatic solution cocktail comprising 4 $\mathrm{mg} / \mathrm{ml} \mathrm{2.5 \%}$ trypsin-EDTA and incubated for 15 minutes followed by $0.1 \%$ trypsin-EDTA for another 15 minutes at $37^{\circ} \mathrm{C}$ in a humidified atmosphere to loosening up the cells bounds of tissue pieces without complete digestion. After the incubation period, the digested tissue pieces were washed with CGM (to stop the action of trypsin). The digested suspension was passed through a double layer of sterile cotton mesh to collect the enzymatic processed tissue. This tissue was directly cultured in $25 \mathrm{~cm}^{2}$ flask and procedure of explant outgrowth was repeated by leaving the flask for 10-15min until complete attachment of enzymatic processed tissue spots and then supplemented with CGM medium composed of L-15 (high glucose) with $2 \mathrm{mM} \mathrm{L-}$ glutamine, supplemented with $20 \%$ fetal bovine serum, 100 $\mathrm{U}$ penicillin/ streptomycin. The entire tissue flask was left undisturbed at $26^{\circ} \mathrm{C}$ in a humidified atmosphere until migration of cells started and reached confluent $(12,15)$.

\section{Cell expansion and sub-culturing}

For both ways of explant methods, cells were allowed to adhere to culture flask and no adherent cells were removed by changing the medium after 3 days of explant date. When the adherent cells reached confluence, covering more than $80 \%-90 \%$ of culture flask, the cells were washed twice with PBS and trypsinized with $0.25 \%$ trypsin-EDTA. After detachment of the adherent cells, suspension centrifuged at $3000 \mathrm{rpm}$ for $10 \mathrm{~min}$, supernatant discarded, cell pellets washed in PBS. Then cells were re-suspended in CGM medium and transferred to new culture flask at a density $10^{3} \mathrm{cell} \mathrm{s} / \mathrm{ml}$. During subculture, they were passaged every 57 days; medium was replaced partially every 2-3 days. Expansion medium consisted of L-15 (low glucose) with 2 $\mathrm{mM}$ L-glutamine, supplemented with $10 \%$ fetal bovine serum, $100 \mathrm{U}$ penicillin/ streptomycin. Adherent cells were cultured until they reached $80 \%-90 \%$ confluence $(12,15)$. For further passaging, sub-culturing procedure was conducted again.

\section{Cells yield}

The number of cells was counted following trypsinisation at the first cell harvest after 85$90 \%$ confluency. The cell yield was calculated by using heamocytometer chamber according to the following formula cited by (26).

Cells $/ \mathrm{ml}=$ average count per square $\times$ dilution factor $\times 10^{4}$

The number $10^{4}$ is the volume correction factor for the hemacytometer chamber: each square is $1 \times 1 \mathrm{~mm}$ and the depth is $0.1 \mathrm{~mm}$.

Total cells in original suspension $=$ cells $/ \mathrm{ml} \times$ total original volume of the whole cell suspension.

To determine the cell growth, cells in different passages were seeded in $25 \mathrm{~cm}^{2}$ tissue culture flasks at a seeding density of $10^{3} \mathrm{cell} / \mathrm{ml}$ and were routinely visualized using an inverted microscope (Axiovert $40 \mathrm{C}$, ZEISS) and the phenotype and growth of primary and passaged cells were monitored. Photomicrographs were taken with a digital camera model of Dino-capture 2.0 (Korea) under inverted phase-contrast optics.

\section{Cell viability of consecutive cell passages}

In P1, cells were plated in tissue culture flasks at a density of $10^{3}$ cells $/ \mathrm{ml}$ and incubated to sub-confluency in CGM medium under standard culture conditions. Subsequently, cells were trypsinised for cell number determination and again plated in tissue culture flasks to 
repeat the steps described above for extra passages. Cell proliferation was assessed in different passages (P1-P7) by determining the relative increase in the number of active cells using a cell count formula shown in the section of cell yield. Growth was determined based on cell counts and splitting ratio per/each passage.

\section{Cell morphology study}

The morphology of unstained cultured cells was examined under inverted microscope (Axiovert $40 \mathrm{C}$, ZEISS) for confluency. Further morphologic identification was investigated by staining the cells with Giemsa stain and examined under light microscope (Olympus Optical Co., Ltd, Tokyo, Japan). Microscopic examination was done according to previously established procedures of (27) for morphology-appearance studies of cultured cells.

Cells Staining: The stain used in this study was Giemsa. Briefly, cells were grown on cover slips in tissue culture Ambi tubes and maintained with L-15 media supplemented with $10 \%$ FBS. After $24-48$ hours of incubation at $26^{\circ} \mathrm{C}$, cells were fixed for 15 seconds with $90 \%$ of alcohol and air dried in a biological hood ( $2 \mathrm{~min})$. Next, the fixed slide was immersed in 5\% Giemsa and left for 2 mins, after which the excess stains were removed by rinsing briefly with small amounts of tap water and placing a piece of paper towel on the stained slide for 1 second. Then, small drop of mounting medium (DPX) was added to the slide and covered with a coverslip.

\section{Results}

\section{Collection of samples}

All randomly selected skin samples for this experiment, showed no external parasites in any of examined fish.

\section{Isolation of cells \\ Explant of Tissue (Direct Procedure)}

Tiny chopped explants of skin tissue of carp fingerlings attached within 1-2 hours post initial seeding in tissue culture flask $\left(25 \mathrm{~cm}^{2}\right)$. Migrated cells grew and formed semi-confluent monolayer by 10 days post culturing (Fig. $1)$.

\section{Explants of Pre-Enzymatic Digested Tissue}

Explants of enzymatic digested tissue showed good attachment of tissue spots within $1 / 2 \mathrm{hr}$ of culturing and cells migration within $24 \mathrm{hrs}$ post initial seeding in tissue culture flask. Cells grew and form confluent monolayer by5-7 days (Fig. 2).

\section{Cell expansion}

There was a difference in proliferation appearance between explants of undigested and digested tissue (especially in initial passages; P1, P2 and P3). In direct explants of undigested tissue, cells on P3 showed irregular clumping of cells and asymmetrical distribution of proliferated cells with many empty gaps in between (Fig. $3)$. The explants of enzymatic digested tissue showed symmetrical, homogenous forming of cell colonies with dense centers as colonized populations for cell proliferation. This cell colonization was observed at the early stages of culturing and in continuing next passages of explants digested tissue spots (until passage 7) (Fig. 4).

\section{Cells yield and viability assay}

Based on the results of trypan blue tests, Live/Dead Viability Assay, cell viability index was calculated for each cell passage (Fig. 5). The highest cell viability index $\left(5 \times 10^{3}\right.$ cells $\left./ \mathrm{ml}\right)$ of pre-digested explants method corresponded to the second cell passage (P2) and continued the successful growth until P4. While cells values of direct tissue explants showed the highest yield $\left(38 \times 10^{2}\right.$ cells / ml) on P4 and declined in number until stopped on P7.

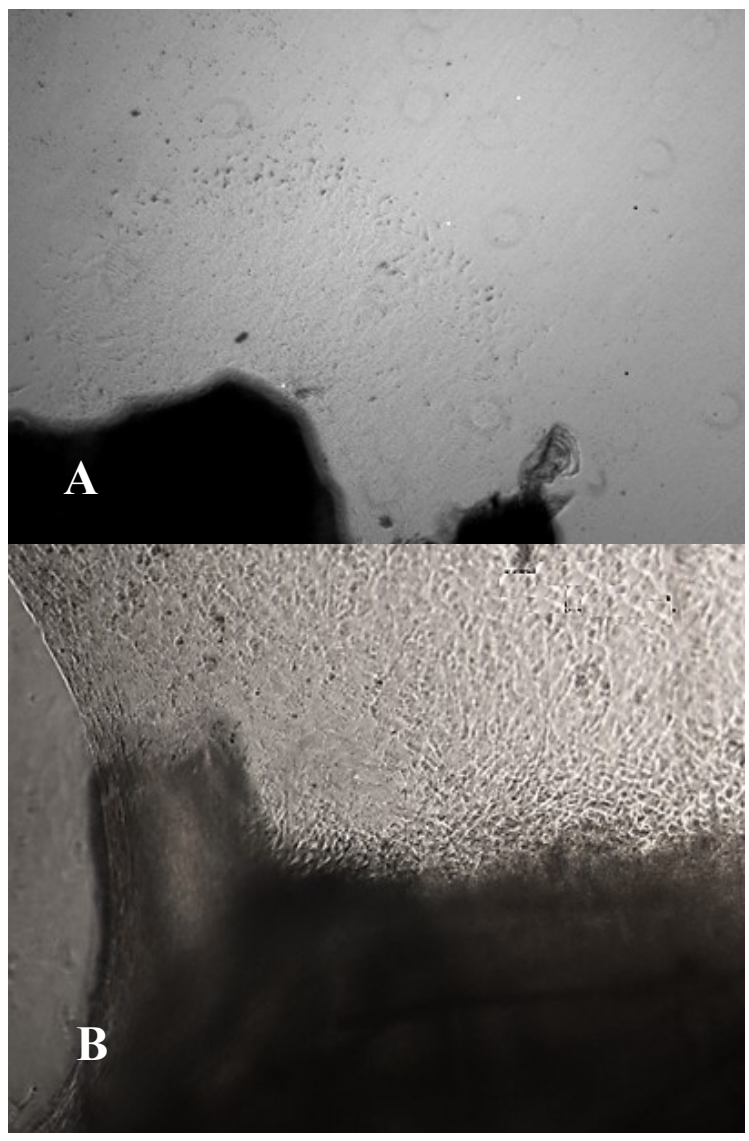

Fig. 1: Explant culture of carp fish skin unstained cells.A: Explants at day 5 post initial culture. B: Explants at day 10 post initial culturing, semi confluent cells (85-90\%). All cells viewed by phase contrast microscope on magnification power 10X. 


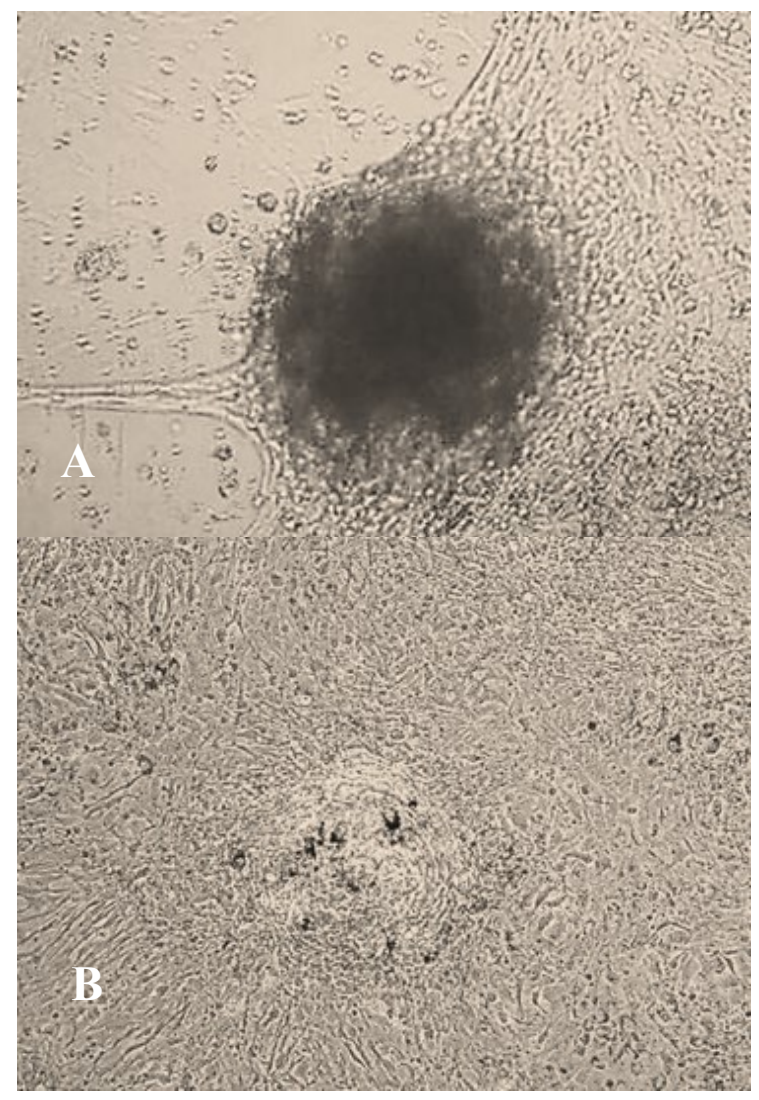

Fig. 2: Explant of enzymatic digested tissue of carp fish skin, unstained cells. A: Explant digested tissue at day 3 post initial culture. B: Explant digested tissue at day 6 post initial culture. Cells are confluent and heterogeneous in appearance. All cells viewed by phase contrast microscope on magnification power $10 \mathrm{X}$.

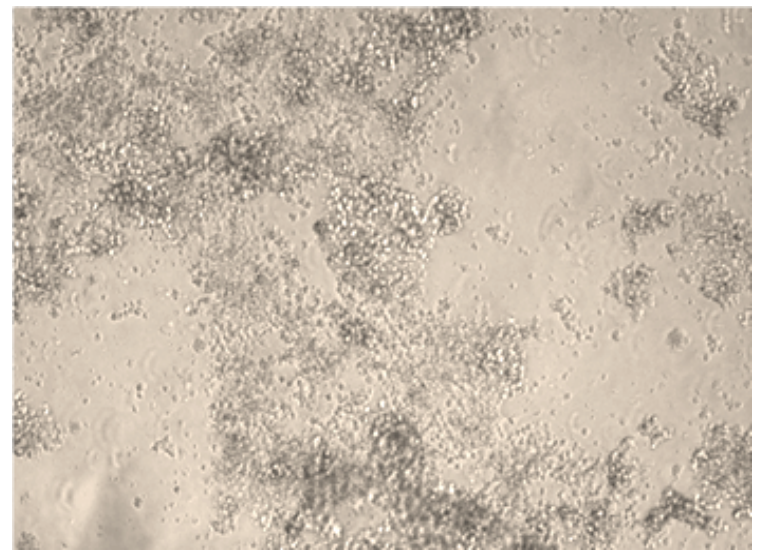

Fig. 3: Explants cells of undigested tissue, cells on P3 showed irregular clumping and asymmetrical distribution of proliferated cells with many empty gaps in between. Phase contrast microscopy, magnification $10 \mathrm{X}$.

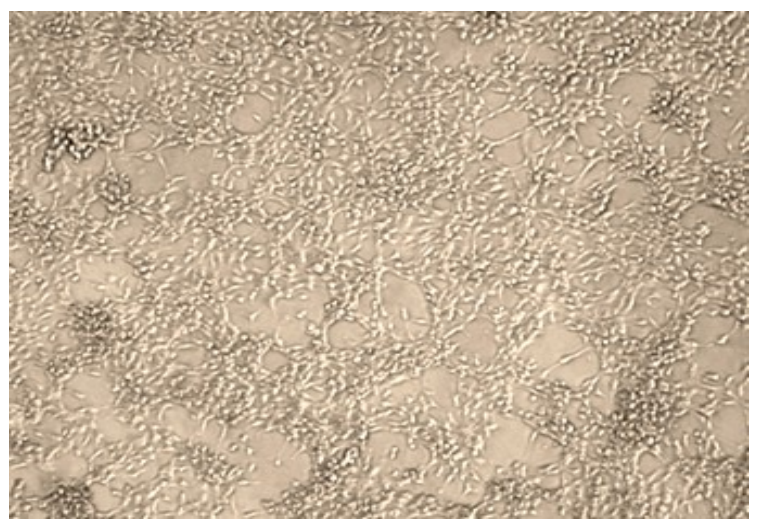

Fig. 4: Explants proliferated cells of enzymatic digested tissue at P3 showed symmetrical, homogenous forming of cell colonies with dense centers as colonized populations for proliferation. Phase contrast microscopy, magnification $10 \mathrm{X}$.

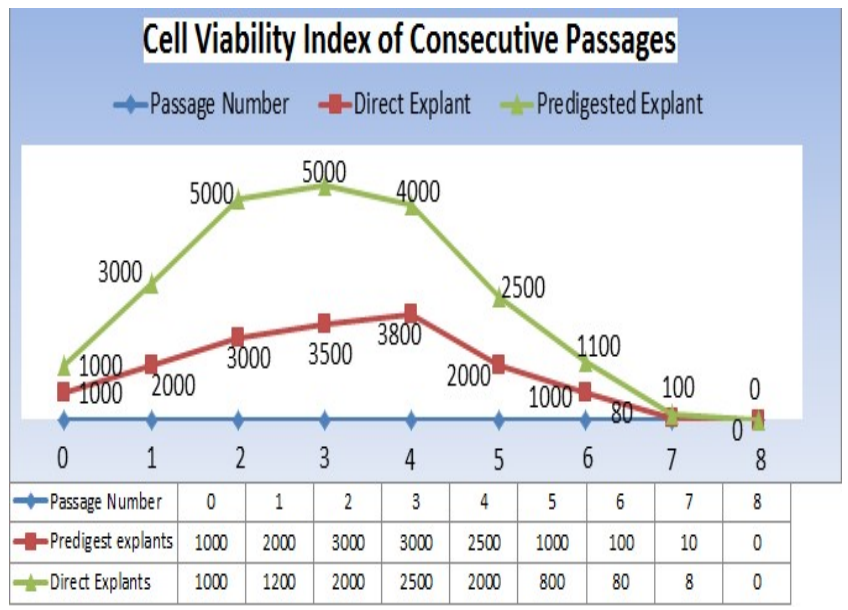

Fig. 5: Cell viability index of 7 consecutive cell passages (P1 to P7) of cells obtained by two methods using trypan blue dye test, LIVE/DEADTM Cell viability assay. The pre-digested explants cells reached the peak of $\left(5 \times 10^{3}\right.$ cells $/ \mathrm{ml}$ ) since $\mathrm{P} 2$ and continued the successful growth until P4 while cells of direct tissue explants showed the highest yield $\left(38 \times 10^{2}\right.$ cells $\left./ \mathrm{ml}\right)$ on $\mathrm{P} 4$ and declined in number until stopped on P7.

\section{Cell morphology study}

The pre-digested explants showed a higher migration potential from the center of clumped cells colonies when compared at the same circumstances of incubation with the corresponding direct explant tissue. Morphological development for cells gained from both protocols showed a gradual change from round to semi oval and coliform appearance in initial two passages and elongated spindleshaped cells was appeared in cultures thereafter (Fig. 6 A, 
B). The spindle-shaped cells continued to proliferate and give a fibroblast -like appearance in further passages (Fig. 7).

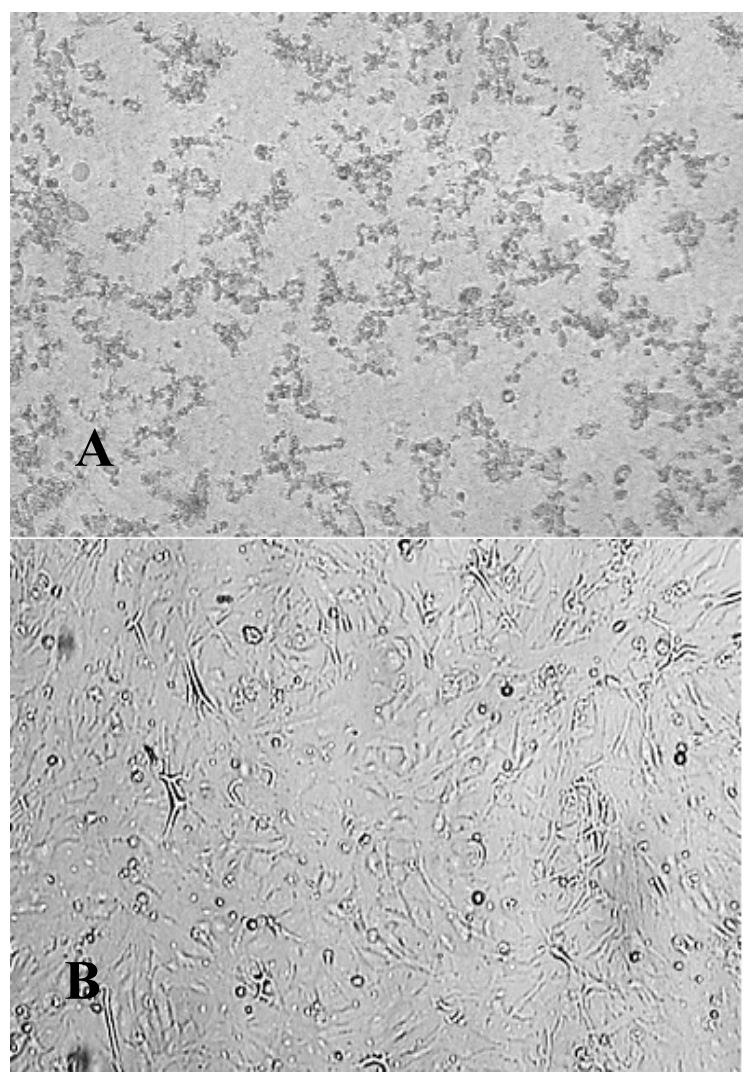

Fig. 6: Morphological development of cells gained in both protocols. A: Cells aged 24hrs on P1, showed roundcoliform appearance. B: Cells aged $48 \mathrm{hrs}$ on $\mathrm{P} 4$, showed a typical shape of fibroblast like cells. Phase contrast microscopy of unstained cells at magnification of $10 \mathrm{X}$.

\section{Discussion}

In present study, the results of primary cells isolation from fish skin tissue indicated that numbers of adherent cells in enzymatic predigested explants protocol were higher and faster that direct explants procedure. Similar results have been reported by (28) about the direct explant cultures have longer processing times and suffer from the no uniformity of cells migration because of improper adherence of tissue fragments to the culture dish, This will result in variability in the quantity and quality of cells obtained (28). Using enzymatic digestion for tissue fragments before explant, results in a more uniform release of cells, it has the only drawback of longer initial processing of tissue (two steps further than direct explant) which may increase the possibility for contamination (29).

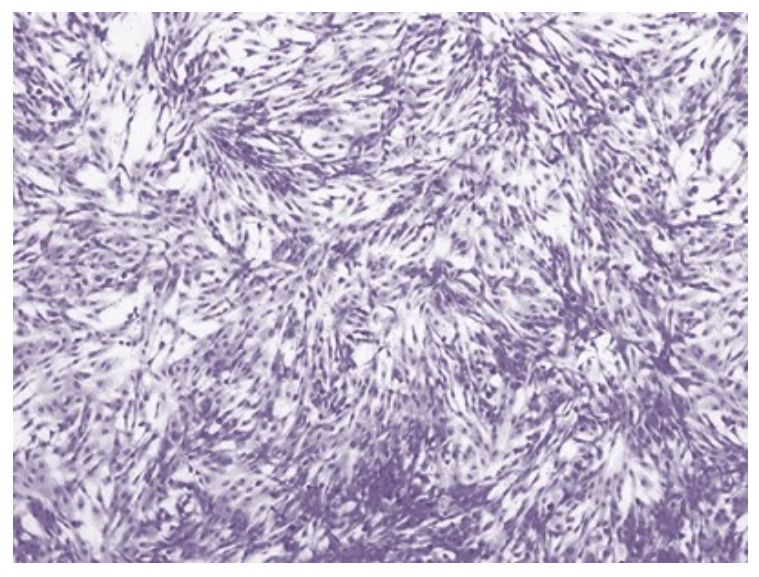

Fig. 7: Explants of predigested enzymatic cells of carp fish skin on P3-P4. Cells stained with Giemsa stain showed a typical appearance of fibroblast -like cells post $48 \mathrm{hrs}$ of sub-culturing. Slides viewed under Olympic Light Microscope on magnification 10X.

Previous reports have indicated that trypsin is a good way to simple mechanical disruption $(28,29)$. Based on this observation, this study used trypsin/EDTA to achieve rapid, uniform and mild disruption of tissue matrix to release the viable cells and have a high cell yield in compare with undigested tissue fragments.

In the present study, $2.5 \%$ trypsin-EDTA were added to tissue fragments of predigested protocol and incubated for 15-20 mints with agitation to gain higher number of cells, followed by FPS inhibition to stop the action of trypsin and promote better growth of cells in cultures. These findings were in consistent with other studies in literature that showed different protocols to isolation of cells from fish skin with different findings. Investigators examined different dose and time of trypsin and collagenase: 2.7 $\mathrm{mg} / \mathrm{mL}$ collagenase type I, $2.5 \%$ trypsin, $3 \mathrm{~h}$ in PBS (15), $0.075 \%$ collagenase type II for $30 \mathrm{~min}, 0.125 \%$ trypsin for $30 \mathrm{~min}(16)$.

When cells migrated from tissue fragments into culture flask, they have round shape cell morphology and changed morphologically into spindle-shaped and fibroblasts like appearance. These features were observed by several studies that found similar development in morphology $(15,16,26)$.

As a conclusion, this study showed that both methods of pre-enzymatic digestion and the direct explant were effective techniques for isolation of primary tissue culture cells from fish skin tissues. However, the cells obtained via pre-enzymatic method displayed higher obtainable cell yield. Such results appear advantageous for cell regeneration in primary cultures. Further investigation to confirm this hypothesis is required. 


\section{Acknowledgment}

The materials needed for this project were provided by the Scientific Research Centre, Faculty of Science, Duhok Univ. and all the work steps have been done in the tissue culture Unit at the Animal Biotechnology lab. of the same centre.

\section{References}

1. Khan EA, Dasmahapatra AK, Rama G. Evaluation of EDTA and fish skin extract in primary culture of fish liver cells. Methods Cell Sci. 1997;19:153-159.

2. Huang CY, Kuo JM, Wu SJ, Tsai HT. Isolation and characterization of fish scale collagen from tilapia (oreochromis $s p$.) by a novel extrusion-hydro-extraction process. Food Chem. 2016;190:997-1006.

3. Sivakumar P, Arichandran R, Suguna L, Mariappan M, Chandrakasan $\mathrm{G}$. The composition and characteristics of skin and muscle collagens from a freshwater catfish grown in biologically treated tannery effuent water. J Fish Biol. 2000;56(4):999-1012.

4. Maitre JL, Valotaire Y, Guguen-Guillouzo C. Estradiol-17ß stimulation of vitellogenin synthesis in primary culture of male rainbow trout hepatocytes. In vitro Cell Develop Biol. 1986;22:337343.

5. Wang SR, Renaud G, Infante J, Catala D, Infante R. Isolation of rat hepatocytes with EDTA and their metabolic functions in primary culture. In vitro Cell Develop Biol. 1985;21:526-530.

6. Ghosh D, Dasmahapatra AK, Ray A K. Primary culture of Prawn hepatocytes in serum free media. In vitro Cell Develop Biol. 1995;(3)1:811-813.

7. Hightower LE, Renfro JL. Recent applications of fish cell culture to biomedical research. J Experim Zool. 1988;248:290-302

8. Blair JB, Ostrander GK, Miller MR, Hinton DE. Isolation and characterization of biliary epithelial cells from rainbow trout liver. In vitro Cell Develop Biol. 1995;31:780-789

9. Dasmahapatra AK, Lee PC. Down regulation of CYP1A1 by glucocorticoids in trout hepatocytes in vitro. In vitro Cell Development Biology. 1993;29A:643-648

10. Ostrander GK, Blair JB, Stark BA, Marley GM, Bales WD, Veltri RW, Hinton DE, Okihiro M, Ortego LS, Hawkins WE. Long-term primary culture of epithelial cells from rainbow trout (Oncorhynchus mykiss) liver. In vitro Cell Develop Biol. 1995;31:367-378.

11. Kaneko Y, Igarashi M, Iwashita M, Suzuki K, Kojima H, Kimura S, Hasobe M. Effects of fish and calf-type I collagens as culture substrate in the adhesion and spreading process of established fish cells. In vitro Cell Development Biol. 1995;31:178-182
12. Klaunig JE, Ruch RJ, Goldblatt PJ. Trout hepatocyte culture: Isolation and primary culture. In vitro Cell Develop Biol. 1985;21:221-227

13. Yamada KM. Cell surface interaction with extracellular materials. Annual Review Bioch. 1983;52:761-799.

14. Akiyama SK, Nagata K, Yamada KM. Cell surface receptors for extracellular matrix components. Biochimistry Biophysics Acta. 1980;1031:91-110.

15. Albelda SM, Buck CA. Integrins and other cell adhesion molecules. FASEB J. 1980;4:2868-2880.

16. Lipsky MM, Sheridan TR, Bennett RO, May EB. Comparison of trout hepatocyte culture on different substrates. In vitro Cell Develop Biol. $1986 ; 22: 360-362$.

17. Piez KA. Characterization of a collagen from codfish skin containing three chromatographically different $\alpha$ chains. Biochem. 1965;4:25902596.

18. Kimura S, Ohno Y. Fish type I collagen: Tissue specific existence of two molecular forms, $(\alpha 1) \alpha 2$ and $\alpha 1 \alpha 2 \alpha 3$, in Alaska pollack. Comp. Biochem. Physiology. 19871;pp:409-413.

19. Kimura S, Ohno Y, Meyauchi Y, Uchida N. Fish skin type I collagen: Wide distribution of an $\alpha 3$ subunit in teleosts. Comp Biochem Physiol. 1987;pp:27-34.

20. Kimura S, Miyauchi Y, Uchida N. Scale and bone type I collagens of carp (Cynprinus carpio). Comp Biochem Physiol. 1991;pp:473-476.

21. Ana L A, Ana LP, Eva M, Tiago HS, Rui LR. Cosmetic Potential of Marine Fish Skin Collagen. Cosmetics J. 2017;4:39.

22. Noga E. Fish Disease. Ames, Iowa: Wiley-Blackwell. 2010.

23. Hasoon M, Daud H, Abdullah A, Arshad S, Bejo H. Development and partial characterization of new marine cell line from brain of Asian sea bass Lates calcarifer for virus isolation. J In Vitro Cell Developm -Anim. 2010;47(1):16-25.

24. Chereen C, Angela T, Christine L, Skye R. Efficacy and Safety of 5 Anesthetics in Adult Zebrafish (Danio rerio). J Amer Assoc Labor Animal Sci. 2014;53(2):198-203

25. Van de Vis H, Kestin S, Robb D, Oehlenschlager J, Lambooij B, Munkner W, Kuhlmann H, Kloosterboer K, Tejada M, Huidobro A. Is humane slaughter of fish possible for industry? Aquacul Res. 2003;34:211-220.

26. Lee EC. Cytogenetic Analysis of Continuous Cell Lines. In The ACT Cytogenetic Laboratory Manual, 2nd ed. (M.J. Barch, ed.). Raven Press, New York. 1991;pp:107-148.

27. Xiaotang HU, Verronika L, Daniel P, Alice N. Lynn MA. Simple and efficient method for preparing cell slides and staining without using cytocentrifuge and cytoclips. Internat J Cell Biol. 2015; Article ID 813216.

28. Ninfa AJ. Fundamental Laboratory Approaches for Biochemistry and Biotechnology. USA. John Wiley \& Sons, INC. 2010;pp:112

29. Dasmahapatra AK, Ray AK, Medda AK. Temperature dependent action of estrogen in singhi fish. Endokrinol.1981;78:107-110. 